\title{
Growth Regulators for Viable Production in Conditions of Formation the Responsible International Cooperation
}

\author{
Tetyana Calinescu ${ }^{1,}$, Olena Zelenko \\ ${ }^{1}$ National aerospace university "Kharkiv Aviation Institute", 61070 Kharkiv, Ukraine \\ ${ }^{2}$ Volodymyr Dahl East Ukrainian National University, 93406 Severodonetsk, Ukraine
}

\begin{abstract}
Scientific and applied discussion of different approaches to socioeconomic development in different societies in the face of world challenges led to formulate such a research goal as a justification of viable production regulators, to recommend the development of other alternatives at all management levels. The methodological basis of the study were the methods and principles of scientific knowledge, general and special methods, techniques used in the justification of production and cooperation regulators. This research made possibility to define the following viability regulators as: the level of knowledge gained, the integration level of the country and its industries for international cooperation; achieving balance in the internal and external environment in terms of profitability and socioeconomic well-being and establishing a social dialogue. The methodological approaches used to identify modern regulators of the production viability have a broad applied aspect of application in various national economy sectors and are original in terms of their use in conditions of responsible international cooperation in Ukraine. The definition of economic growth targets in Ukraine should be based on: human capital sustainable development; formation of effective communications at all government levels in order to synchronize the actions and changes in the development of responsible international cooperation.
\end{abstract}

\section{Introduction}

Viability in any aspect of development can be seen as the ability to develop and solve existing problems. Due to endless attempts to reform the economy of Ukraine in the face of constantly emerging European and world challenges [1-3], viable innovative potential of production is lost and negative tendencies appear for the deterioration of the socio-economic status for the country, individual territories, conformity of production for the results of its activities. loss of national identification of society.

However, the founding fundamental provisions for balanced development of Ukraine until 2030 [4-6] require a reorientation to other value components that take into account formal and informal, quantitative and qualitative factors of growth, international and interstate points of socio-economic collision, widening the boundaries of functioning and forming new alternatives development, scientific and practical conscious international cooperation. Contradictions, political debate over different approaches to socio-economic development, the presence of conflicts in Ukrainian society make it necessary to expand and justify other regulators of viable production and alternatives for responsible development and cooperation at the micro, macro and meso levels.

\section{Results}

Each country undergoes several stages in the process of internationalization and integration of its own relations into the global socio-economic community [7]:

1) political internationalization - adaptation of state policy to world standards by signing and ratifying relevant agreements, conventions, declarations adopted at the international level;

2) social integration - the gradual establishment of social relationships between specific social communities of one country and relevant social communities in other countries of the world;

3) scientific and technological integration - involves interaction at the level of specific enterprises, regional associations of different countries, and global scientific and technical integration, cooperation against the background of the implementation of specific strategically important for humanity projects;

\footnotetext{
* Corresponding author: tetyana.calinescu@gmail.com
} 
4) environmental integration - is realized through the creation of a legal, regulatory and methodological base harmonized with world standards and an organizational structure that will meet the requirements of national and world environmental security;

5) economic integration - this aspect of internationalization and globalization is implemented in parallel with social, scientific, technical and environmental integration, it is their integral base, which ensures the sustainability of these processes; provides for the convergence and deepening of the interaction between national economic system of different countries in the world, manifested through production, trade, financial investment and infrastructure integration.

The problem of successful integration of the national economic system into the world system of economic relations is addressed by a whole galaxy of scientists. While paying due attention to the current scientific and practical base of the researches carried out $[5,6,8,9]$ and those carried out within the framework of state-approved topics in different universities ${ }^{2}$, with the direct participation of authors $[9,10]$, it should be emphasized that the developed methodologies are aimed at ensuring stability, social sustainability, socialization of production, and although they raise awareness and responsibility for the results of their activities, but the level of development and investment in those aspects of socio-economic activity that supports the development of consciousness Bridges and responsibility in society, although increasing, but still does not bring positive results. So:

1. In 2019, funding from the budget for social assistance (16.5\%), education (17.6\%), health care $(21.0 \%)$, etc. increased slightly. And they make up mostly $18.2 \%$ [11], but against the background of low per capita income growth, ever-increasing labor migration and inflation, all any socio-economic achievements in the country are nullified.

2. Education reforms implemented in Ukraine since 2016 in higher and general education have also shown that education is funded at a minimum [12], and in the context of a general impoverishment of the population, these funds are insufficient to support the development of modern consciousness among the population.

3. The growth of productive activity in the financial and insurance market, construction, telecommunications, transport and logistics, agriculture and forestry [13]. And almost the last position is occupied by the industry, where today there are significant restructuring of markets, energy carriers, transition to the production of import-substituting products, energy-saving technologies. And the debate in the Verkhovna Rada on lifting the moratorium on the sale of land - creates additional socio-economic conflict situations in Ukrainian society.

4. Disruption of economic ties with Russia and the withdrawal of Ukraine from the Customs Union brings additional difficulties in forming new directions of international cooperation in various spheres of socio-economic activity and calls for not only their national identity, but the security of the state, production, etc.

\section{Discussion}

Of course, the already proposed approaches to managing economic development, reducing unemployment, inequalities and changes and the situation in the environment, support and integration, the creation of new forms of international cooperation $[1,3,4,6]$ can be considered as the main vector to guide the movement country, its national production to certain landmarks. However, it should be said that, even in any deliberate document, there are drawbacks (miscalculations) that are related to the specific development of any country, territory and society. Therefore, in each case, regulators should be found, the existing economic potential adjusted to the requirements of modern business and the need to stabilize positive development should be adjusted.

The world history of the development of economic systems in parallel with purely economic indicators of development considers such a concept as "human dimension" [14] - a term that was originally used by philosophical concepts of the development of life, implies the formation of a general picture of the world with a focus on the human community. The life activity of each individual person is conditioned by certain socio-cultural characteristics and the outlook in society that is specific to each historical epoch. Economic culture is a part and basis of economic activity of a particular individual, their totality, the state as a whole. Accordingly, without a clear understanding of what constitutes a system of economic relations, in what form, and in the future, the economic culture of mankind, which is a powerful aggregate resource of the societies

2 Themes: "Development of democratic mechanisms for self-sufficiency of socio-economic transformations of society" (state registration number 0116U004159), which was carried out at the Volodymyr Dahl East Ukrainian National University. in 2016 - 2018; "Methodology for socioeconomic, information and scientific and technological development of regions, industries, enterprises and associations" (state registration number 0116U006782), which was implemented at the National Metallurgical Academy in 2016 - 2018; "Modern Determinants of Finance and Accounting Development in a Systemic Crisis" (State Registration Number 0118U004462), followed by research at the National Aerospace University "Kharkiv Aviation Institute" in 2018 2020. 
of individual countries and humanity as a whole, cannot solve the main global problem - ensurin a decent level life for every individual on the planet.

In Fig. 1. the place of Ukraine among other countries of the world according to some indices of global development during the last decade, which in one way or another characterize certain aspects of sustainability in development context for socio-economic society of the country in the international plane is presented.

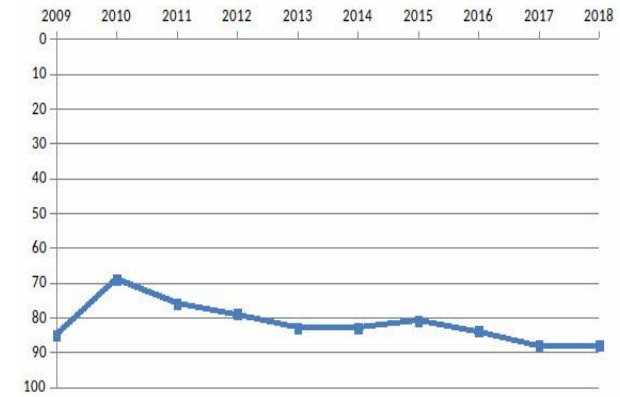

1. Human Development Index

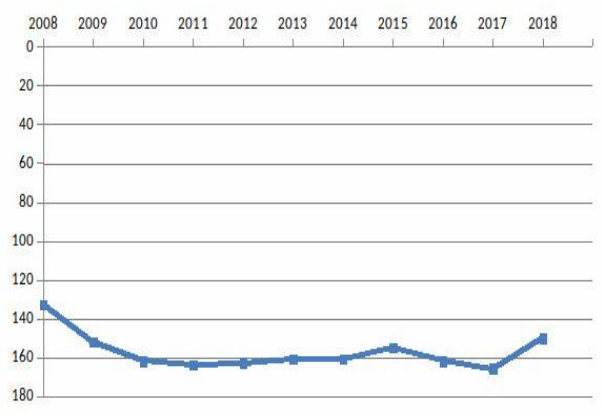

3. Index of Economic Freedom

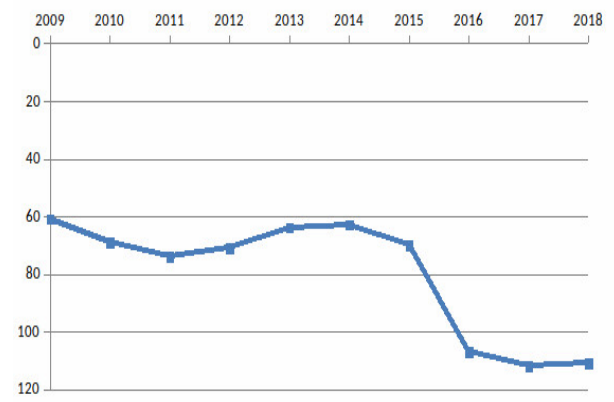

2. Prosperity Index

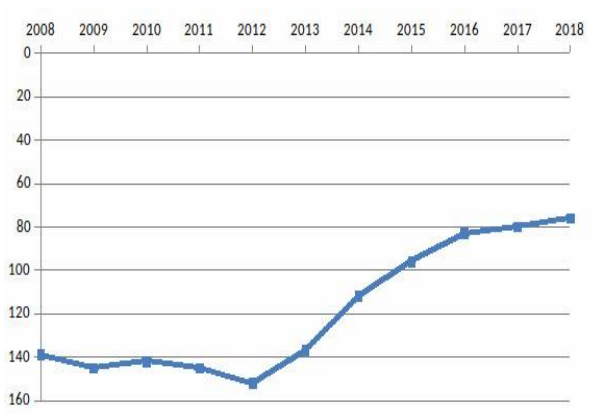

4. Ease of Doing Business Index

Fig. 1. Ukraine's place in the global rankings in 2008-2018 [15].

The first of these indicators is the Human Development Index, which enables a comparative assessment of poverty, literacy, education, life expectancy, health, social protection, longevity, environmental status, crime rate, respect for human rights and freedoms, and GDP per capita. Taken together, in all these respects, Ukraine has not actually moved from a "dead end": a significant improvement in the situation in 2010 was completely leveled over the next 8 years and in 2018 the country took 88 steps, which is worse than the result of 2009. It deserves special attention. GDP per capita (Table 1).

Table 1. The leading countries in GDP per capita in 2018 [16].

\begin{tabular}{|c|c|c|}
\hline № & Country & US \$ \\
\hline 1 & Luxembourg & 114,341 \\
\hline 2 & Switzerland & 82,839 \\
\hline 3 & Norway & 81,807 \\
\hline 4 & Ireland & 77,450 \\
\hline 5 & Iceland & 73,191 \\
\hline 6 & Qatar & 69,027 \\
\hline 7 & Singapore & 64,582 \\
\hline 8 & USA & 62,641 \\
\hline 9 & Denmark & 60,596 \\
\hline 10 & Australia & 57,305 \\
\hline$\ldots$ & $\ldots$ & $\ldots$ \\
\hline 122 & Ukraine & 3,095 \\
\hline
\end{tabular}

According to the World Bank, as of 2018, per capita GDP, Ukraine ranked 122 among 181 countries in the world, almost on par with the Philippines and the Micronesian Federations.

The second indicator presented in Fig. 1, - the prosperity index is a comprehensive indicator calculated on the basis of more than one hundred simple indicators, which in turn are grouped into such categories as: economic development, doing business, government, education, health care, security of life, personal freedoms, social capital, ecology. According to the prosperity index, Ukraine has moved from the sixth to the second ten in the last ten years over the last ten years, and despite a slight improvement (111th position in 2018 compared to 112th in 2017), it remains almost 
at the end of the ranking. The worst situation in the healthcare country is the last 137 th place in this group.

The third indicator, the dynamics of which is presented in Fig. 1, is an index of economic freedom, which means the fundamental right of every person to manage his or her own work and property. The Economic Freedom Index is calculated on the basis of ten simpler indices, namely: the level of business freedom, trade freedom, tax freedom, public spending, financial investment and monetary freedom, the level of property rights protection, freedom from corruption and the level of freedom of employment. According to the results of the rating, five groups of countries are distinguished: free economy, mainly free economy, moderately free economy, free and depressed economy. Analyzing the data in the chart above, it is worth noting that Ukraine has never even had a moderately free system of economic relations. Being in the group of countries with a free economy, as a result, in recent decades the country has only worsened its figure by 10 positions.

The last, quite optimistic graph in Fig. 1 shows the dynamics of Ukraine's place among other countries in the world by the ease of doing business index. Despite the existing problems in the system of economic relations, it is recognized by the world community that Ukraine is confidently moving towards improving the conditions of business project implementation. The index covers such indicators as: the level of complexity at the start of the project, the complexity of completing procedures for obtaining all permits, ensuring energy supply, registration of property under the project, the complexity of obtaining credit, the level of protection of the rights of project investors, tax burden, complexity of export-import procedures, penalties sanctions for payment of debt obligations and conditions for closing a business project. For the period 2009-2018, Ukraine has overcome sixty steps by the ease of doing business index, moving from 145 to 76 positions.

Today, Ukraine has sufficiently different examples of growing development that most industries try to adapt to their activities, but any economic development depends on the knowledge of the technologies of innovation, the level of consciousness and responsibility of the team (society), which introduces them. This means that viability regulators, such as the acquisition of knowledge, continuous training throughout the active life, the acquisition of certain skills in those countries where any experience comes from, should be put at the forefront. And this knowledge transfer is not an automatic process that is only related to the education system, advanced training, grants from international organizations for the development of new technologies of development, internships and training in other countries on the basis of long-term international cooperation, etc. And it requires understanding that there are some differences in education, worldviews, national traditions and culture. What then creates the consciousness of society and its responsibility for the current level of development.

Secondly, the economy of any country or production is developing not in a vacuum but in the environment of the economies of different countries. Therefore, future growth depends on the effective coordination of international cooperation, structural change and the aspirations of each country to balance and integrate its internal goals with international ones. This requires not only the readiness of the country and its society for the necessary transformations in the economy, the structuring of national production, but also a responsible conscious attitude to the changes that are taking place in the global environment and international economic policy.

Thirdly, none of the factors affect the consciousness of the population any more, such as raising their income level. This entails restructuring individual industries at the macro level, changing the pattern of growth and income inequalities at the macro level, raising awareness of innovative investments (eg in education, energy saving and processing industries) and taking responsibility for the steady growth and achievement of balance in the internal and external environment.

Fourth, achieving a different level of income, the emergence of new types of influence, responsibility are associated with the emergence of new pressures and conflicts in the internal and external environment, because new successes are not uniquely perceived and do not always open up greater opportunities for society. Therefore, regulators of socio-economic well-being, such as social dialogue, the creation of public (collective) domestic or international treaties, etc., should be used.

State doctrines and programs for the development of production in Ukraine provide for the functioning of effective regulators of development of the national economy, in particular in the field of education, the creation of effectively developed social and human capital, effective network communications, etc., which should be attributed [4, 17]:

1) social partnership of science, education, business, government and wide participation of society. It is precisely the construction of harmonious interconnections between them that will make it possible to obtain a balanced socio-economic policy of the state for the benefit of the whole society.

2) the largest national assets (that is, which must be constantly monitored and regulated) are the level of financial and legislative support, the development of science, education and manpower,

3 ) increasing responsibility for the rational use of scarce natural resources, pollution of the environment;

4) establishing a constructive dialogue between the authorities and representatives of business circles, business and employees; 
5) creating conditions for the reproduction and development of human capital, ensuring attention to the preparation of engineering, scientific and working personnel, improving the professional qualification of employees;

6) in order to take into account, the current global challenges and advantages, it is necessary to create conditions for innovative development of industry and to identify mutually beneficial directions of international cooperation not only with the EU, but also with other countries, and more.

Today's economy of Ukraine has a multi-vector orientation [18], namely, different regions gravitate to different foreign markets: Eastern regions - to the Eurasian market, Southern - to the Asian and African markets, Northern and Central regions - to the European, Asian and African markets, the Western regions are focused solely on Europe. Therefore, the development processes of these regions should be focused not only on studying the experience of transformation of these countries, but also consider the elements of their healthy vitality in the education and development of human capital.

\section{Conclusion}

1. The current state of the Ukrainian economy demonstrates the urgent need to develop regulators of the country's growth trajectory, taking into account the possibilities of adapting to the existing acute internal and external challenges. In this context, considerable attention should be paid to the formation of an effective mechanism for ensuring the viability of national production, the establishment of responsible cooperation in all branches of management, the definition of targets for economic growth in Ukraine, considering current trends in the development of the world economy, international cooperation.

2. In a time of transformation in the face of today's global challenges, there is a search for viable new development trajectories, but the need for sustainable and reliable production and balanced economic development remains constant. The specificity, complexity and variability of the conditions in which changes in the direction of effective socio-economic growth are taking place must be considered.

3. The basis of viable development is human capital, which can establish effective communication in the internal and external environment, take into account the experience of generations, direct the accumulated knowledge on responsible, careful attitude to its activity, ensuring the stable functioning of the economy, stability of various levels of communication and fulfillment of obligations. through various collaborations.

4. Responsible co-operation is formed through effective links in the internal and external environment, which should be built on the principles of heterarchy, which includes the formation of linear horizontal and vertical functional links at all communication levels and will ensure the formation of an accessible information network, where each of the parties may have access to make the right responsible decisions.

5. Participation in international cooperation requires not only a responsible attitude, but also synchronization of actions in accordance with the scale of change, independence, empowerment, pragmatism and cooperation in conflict management.

\section{References}

1. G. Maxton, J. Randers. Reinventing Prosperity. Managing Economic Growth to Reduce Unemployment, Inequality and Climate Change. A Report of the Club of Rome. (Kyiv: Pabulum) 2017

2. M. Friedman \& R. Friedman. Capitalism and Freedom. (Kyiv: Our format, 2017)

3. M. Spence. New Convergent. (Kyiv: Tempora) 2017

4. Ukraine 2030: Doctrine of the balanced development. (Lviv: Kalvaria) 2017

5. L. S. Gurianova. Design of the balanced socio-economic development of regions. (Berdiansk: PPB Tkachyk O.I) 2013

6. G. J. Kucherova, Strategy of forming of conscious taxation as factor of steady development of national economy. (Zaporizhzhya: CPU) 2016

7. P. O. Kutsik, O. I. Kovtun, G. I. Bashnianin, Global Economy: Principles of Formation, Functioning, Regulation, and Development: monograph. (Lviv: LKA) 2015

8. Experience of association of territorial communities on East of Ukraine: economical and legal aspects V.A. Ustimenko, I.V. Zablodska (Ed.). Kyiv: LTD «VISTKA», 210 (2018)

9. T. Calinescu, \& G. Likhonosova, \& O. Zelenko. Manifestation Trend of the Behavioral Economy in Ukraine by of the 33 International Business Information Management Association Conference (IBIMA), 10 - 11 April 2019, Granada Spain. Education Excellence and Innovation Management through Vision: Editor Khalid S. Soliman. Available at: https://ibima.org/conference/33rd-ibima-conference/\#ffs-tabbed-15/ (2020)

10. T. Calinescu. M \& E. Vol. 1, Tom 15. Burgas: University of «Prof., dr. Asen Zlatarov», Bulgaria, 38 - 45. (2019)

11. A. Kramar. The Ukrainian Week, 1'(143), 30 - 31 (2020)

12. A. Kramar. The Ukrainian Week, 12`(142), 28 - 30. (2019)

13. L. Shavalyuk. The Ukrainian Week, 11(141), 30 - 32. (2019) 
14. O. V. Bondarenko, Gileya. 107, 286-291 (2016)

15. Ukraine in International Ratings Available at : https://uiamp.org.ua/ukrayina-vmizhnarodnih-reytingah(2019)

16. List of countries by GDP (nominal value) per capita Available at : https://uk.wikipedia.org/wiki/ (2019)

17. State program of domestic production development. Approved by the Resolution of the Cabinet Ministers of Ukraine. September 12, N 1130. Available at : http://search.ligazakon.ua/1_doc2.nsf/link1/KP111130.html(2011).

18. A. Kramar. The Ukrainian Week, 10, 27 - 29 (2019) 